IZA DP No. 7305

\title{
The College Type:
}

Personality and Educational Inequality

Shelly Lundberg

March 2013 


\title{
The College Type: Personality and Educational Inequality
}

\author{
Shelly Lundberg \\ University of California, Santa Barbara, \\ University of Bergen and IZA
}

Discussion Paper No. 7305

March 2013

IZA
P.O. Box 7240
53072 Bonn
Germany

Phone: +49-228-3894-0

Fax: +49-228-3894-180

E-mail: iza@iza.org

Any opinions expressed here are those of the author(s) and not those of IZA. Research published in this series may include views on policy, but the institute itself takes no institutional policy positions. The IZA research network is committed to the IZA Guiding Principles of Research Integrity.

The Institute for the Study of Labor (IZA) in Bonn is a local and virtual international research center and a place of communication between science, politics and business. IZA is an independent nonprofit organization supported by Deutsche Post Foundation. The center is associated with the University of Bonn and offers a stimulating research environment through its international network, workshops and conferences, data service, project support, research visits and doctoral program. IZA engages in (i) original and internationally competitive research in all fields of labor economics, (ii) development of policy concepts, and (iii) dissemination of research results and concepts to the interested public.

IZA Discussion Papers often represent preliminary work and are circulated to encourage discussion. Citation of such a paper should account for its provisional character. A revised version may be available directly from the author. 


\section{ABSTRACT}

\section{The College Type: Personality and Educational Inequality ${ }^{*}$}

I examine the effects of cognitive ability and personality traits on college graduation in a recent cohort of young Americans, and how the returns to these traits vary by family background, and find very substantial differences across family background groups in the personality traits that predict successful completion of college, particularly for men. The implications are two-fold. First, the returns to noncognitive traits may be highly contextdependent. Second, policy discussion concerning educational inequality should include, not just the possibilities for remediating the skill levels of poor children, but also approaches to changing the environments that limit their opportunities.

JEL Classification: $\quad 124$

Keywords: education, personality, inequality

Corresponding author:

Shelly Lundberg

Department of Economics

2127 North Hall

University of California

Santa Barbara, CA 93106

USA

E-mail: lundberg@econ.ucsb.edu

\footnotetext{
* This paper is based on my presidential address at the 2012 Society of Labor Economists meeting in Chicago. I would like to thank Richard Startz, Glynis Startz, Meredith Startz, seminar participants at UCSB, University of Wisconsin, University of Illinois, University of Colorado, Boulder, Washington University in St. Louis, and the 2012 SOEP Users Conference, the editor and an anonymous referee for many valuable comments. I also appreciate the assistance I've received from Jennifer Milosch and Jarrett Gorlick.
} 


\section{Introduction}

Formal education is an important mechanism by which economic privilege is passed from one generation to another: the children of high-income, well-educated parents are very likely to stay in school themselves and reap the benefits from that investment. In the United States, disparities in educational attainment by family background appear to have been growing in recent decades. College completion rates rose by 18 percentage points for young men and women born around 1980 in high-income families compared to cohorts from the early 1960s, but increased by only 4 percentage points for low-income youth, and the income gap in college entry rates has also increased (Bailey and Dynarski, 2011). It is not clear why children from families at the top are pulling away from those at the bottom in educational attainment, but increases in educational persistence are likely to contribute to declining levels of intergenerational mobility.

Most discussions of educational inequality focus on the skill deficits, both cognitive and noncognitive, of youth from low income households and on interventions that can prevent or remediate inherited inequalities in productive traits. We do know that large SES gaps in skills and behavior are present when children enter school, and these gaps tend to persist or to grow larger with age (Duncan and Magnuson, 2011). ${ }^{1}$ Differences across family income groups in measures of academic achievement such as test scores have grown substantially over the past four decades (Reardon, 2011). Less attention has been paid to how the environments that children face interact with their skills to determine school success. Family background and family resources affect not only the skills that students bring to school, but also the environment in which these skills are deployed. Interactions between skills and environment may be particularly significant if traits that are conducive to educational achievement differ systematically across school, family, or social contexts. For instance, if individuals from advantaged and disadvantaged backgrounds experience different payoffs to persistence or to sociability, then the set of traits that defines the 'college type' may differ by socioeconomic status as well.

In this paper, I examine the effects of cognitive ability and personality traits on college graduation in a recent cohort of young Americans, and how the returns to these traits vary by family background. A simple model of schooling choices with family or community inputs that interact with stable individual traits shows that we can expect otherwise identical students who are in different situations to have different educational outcomes. I find very substantial differences across family background groups in the personality traits that predict successful completion of college, particularly for men. Conscientiousness, which has been linked in past research to school success, has no significant impact on the education of disadvantaged men, while openness to experience is an important correlate of college graduation only for less-advantaged men and women.

These results indicate that environments influence the returns to psychological traits, and suggest that the route to educational success is very different, and so calls on different capabilities, for identical children from advantaged and disadvantaged socioeconomic groups. For most children who have prosperous and well-educated parents, the path to higher education is a straightforward one and, as previous research has indicated, the returns to a trait related to stability and persistence (conscientiousness) are

\footnotetext{
${ }^{1}$ Both cognitive skills and socio-behavioral (or 'noncognitive') skills are affected by early environment and are important for important economic outcomes (Heckman, Stixrud, and Urzua, 2007). The technology of early skill formation is an important area of economic research (Cunha, Heckman, and Schennach, 2010; Todd and Wolpin, 2007) and may provide a rationale for increasing investments in the early education of disadvantaged children (Heckman and Masterov (2007).
} 
substantial. There is no apparent payoff for these children, however, to imagination and creativity (openness). The converse is true for disadvantaged young men. There are other interpretations of these patterns, but all imply starkly different paths to college for youth from high- and low-income families. Personality, which is highly heritable, may be a proxy for parental personality or other unobserved influences on educational success that have SES-dependent returns. Finally, if adult personality is shaped by the educational process, this transformation must differ in kind, not just degree, by family background.

The implications of this rather preliminary set of findings are two-fold. First, the returns to socioemotional and other noncognitive traits may be highly context-dependent, and we need to know much more about which characteristics can be regarded as skills that can and should be enhanced, and in what environments. Second, policy discussion concerning educational inequality should include, not just the possibilities for remediating the skill levels of poor children, but also approaches to changing the environments that limit their opportunities.

\section{Educational Attainment of a Young American Cohort}

The socioeconomic gradient in educational attainment can be seen in the recent cohorts of young men and women followed by the National Longitudinal Study of Adolescent Health (Add Health). ${ }^{2}$ The Add Health study began in 1994-95 with a nationally-representative, school-based survey of more than 90,000 students in Grades 7 through 12. About 20,000 respondents were followed in subsequent surveys, the last of which (Wave IV) was conducted in 2007-08 when the respondents were between 24 and 32 years of age. The survey content is very rich, initially focusing on the forces influencing adolescent health and risk behaviors and then broadening in scope as the respondents transitioned into adulthood. By Wave IV most, though not all, of the respondents will have completed their formal education. In the analyses that follow, I use a subsample of 7748 women and 6795 men for whom all key variables are non-missing.

The socioeconomic status of each individual in the sample is defined in terms of two simple family background variables: mother's educational attainment (some college or more vs. high school or less), and an indicator for whether the respondent lived with both biological parents at Wave I of the survey. Group 1, with high maternal education and residence with both biological parents, is the most advantaged, and Group 4, with low maternal education and non-residence with both biological parents, is the least advantaged. Group 2 includes respondents with high maternal education who did not live with both parents in middle school, and Group 3 is defined by low maternal education but residence with both biological parents. Alternative indicators of SES or parental resources could be constructed on the basis of paternal education, family income at Wave I adjusted for family size and composition, or mother's age at birth. Father's education, however, is not available for a substantial proportion of the sample (including many of the 45 percent of the sample who were not living with both biological parents at Wave I) and, since parents have been interviewed only once, no long-term measures of family income are available. Mother's

\footnotetext{
${ }^{2}$ Add Health is a program project directed by Kathleen Mullan Harris and designed by J. Richard Udry, Peter S. Bearman, and Kathleen Mullan Harris at the University of North Carolina at Chapel Hill, and funded by grant P01HD31921 from the Eunice Kennedy Shriver National Institute of Child Health and Human Development, with cooperative funding from 23 other federal agencies and foundations. Special acknowledgment is due Ronald R. Rindfuss and Barbara Entwisle for assistance in the original design. Information on how to obtain the Add Health data files is available on the Add Health website (http://www.cpc.unc.edu/addhealth). No direct support was received from grant P01-HD31921 for this analysis.
} 
education and Wave I living arrangements are available for almost all respondents and can be expected to be strongly correlated with household permanent income and with family stability throughout childhoodtwo key determinants of the resources available to children.

Figure 1 shows substantial gaps in college attendance and college completion rates across family background groups for both Add Health men (top panel) and women (bottom panel) at Wave IV. Both maternal education and family structure matter for educational attainment and, in addition to the SES gradient, we can see in this figure the educational gender gap that characterizes recent cohorts of young Americans. In the advantaged Group 1, 65 percent of women and 51 percent of men have acquired a fouryear college degree or more, compared to 40 and 29 percent, respectively, in Group 2, 31 and 23 percent in Group 3, and only 17 and 12 percent in Group $4 .^{3}$ Similarly, the proportion of young men and women with only a high school education or less rises as we move from the most to the least advantaged family background group.
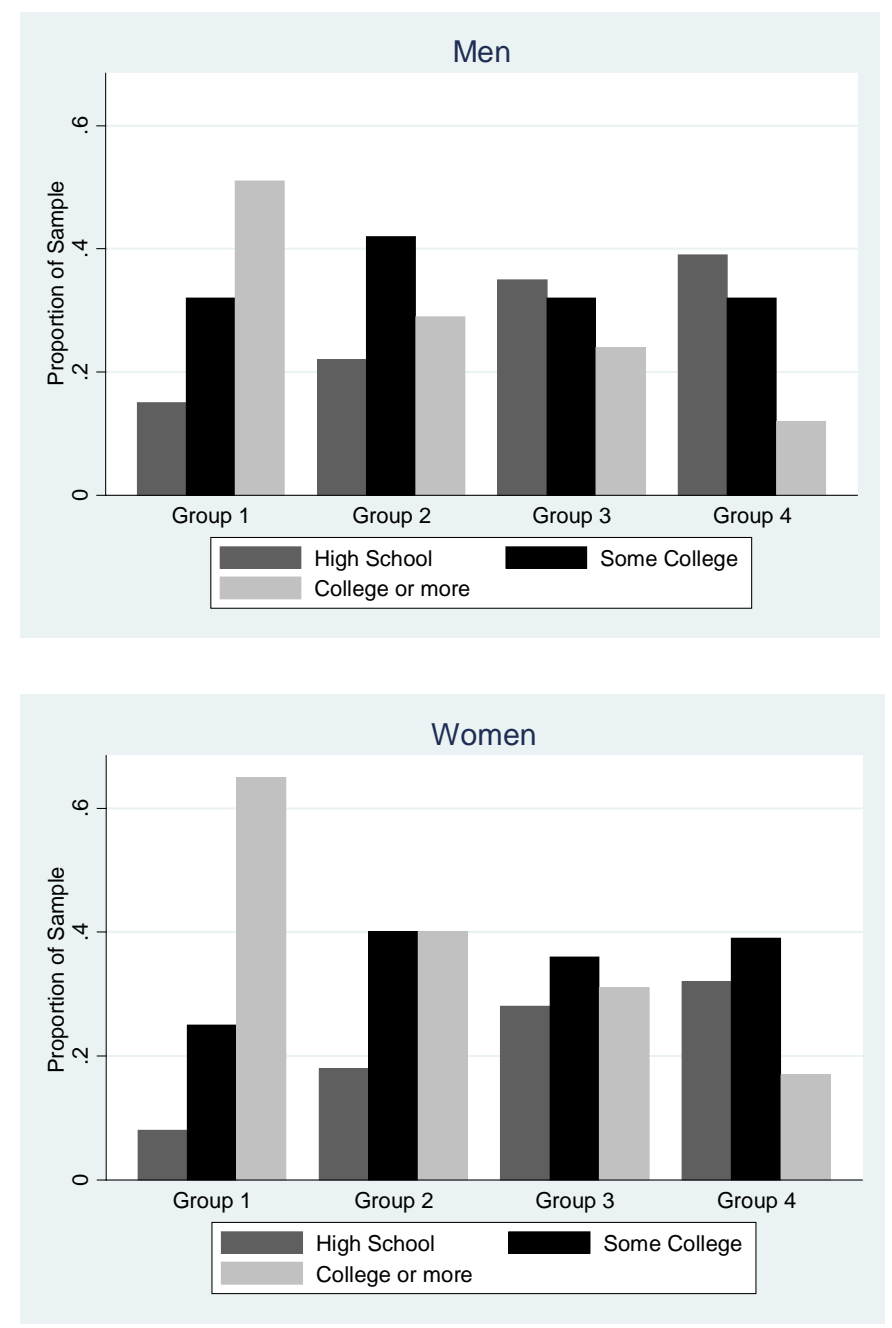

Figure 1: Educational Attainment of Add Health Men and Women at Wave IV by SES Group (Group 1=high, Group 4=low) ${ }^{3}$ As a comparison, 2011 Current Population Survey data shows 37 percent of women aged 25 to 34 with at least a 4-
year college degree, and 29 percent of men. 
I will be focusing here on the determinants of 4-year college graduation, though the key findings apply more generally to other educational transitions such as college entry (Lundberg, 2012). U.S. college graduation rates have not grown in the past 30 years although the earnings premium associated with a college degree has increased substantially. College graduation is a particularly interesting outcome, since low rates of college completion, conditional on enrollment, distinguish tertiary education in the United States relative to other developed countries (Bound and Turner, 2011), and the disparity in college completion rates by parental circumstances has been growing (Bowen, Chingos, and McPherson, 2009). Bound and Turner (2011) review the possible causes of the cessation of growth in college graduation, including inadequate preparation of students for college and the declining availability of college funding and resources. They emphasize that there is much we do not know about individual college choice and persistence, including how much information students have about the consequences of and required preparation for a particular educational program, the role of parents and the school in providing information and helping students qualify for, apply to, and successfully complete college.

\section{Cognitive and Noncognitive Skills}

The experiences of the Add Health cohorts are consistent with a large and growing literature on intergenerational mobility that has documented a strong (and possibly increasing) correlation between the earnings and education of parents and their children (Black and Devereux, 2011). What are the mechanisms that tie the economic success of parents to the economic success of their children? Highresource parents do, of course, make direct investments in the earnings capacity of their children by purchasing high-quality education, providing jobs or job connections, or making business loans, but one important pathway from parental achievement to child achievement is clearly through the heritability of IQ and other traits that enhance productivity, such as persistence and social skills. This inheritance can be transmitted genetically or through a child-rearing environment in which parents can pass on skills and behavioral tendencies through training or example. One underpinning of the SES differences in educational attainment in the Add Health sample is likely to be the relationship between the cognitive and 'noncognitive' skills of parents and children.

Cognitive ability: Measures related to cognitive ability, such as IQ scores and academic achievement tests, are strongly predictive of outcomes such as educational attainment and also, both directly and indirectly, labor market outcomes such as wages (Cawley, Heckman \& Vytlacil, 2001; Gottfredson, 2008). In Wave I, the Add Health Picture Vocabulary Test (an abridged, computerized version of the verbal ability measure, the Peabody PVT) was administered, and this measure of the cognitive skills of the respondents varies by SES group in the expected way, as shown in Figure 2. 


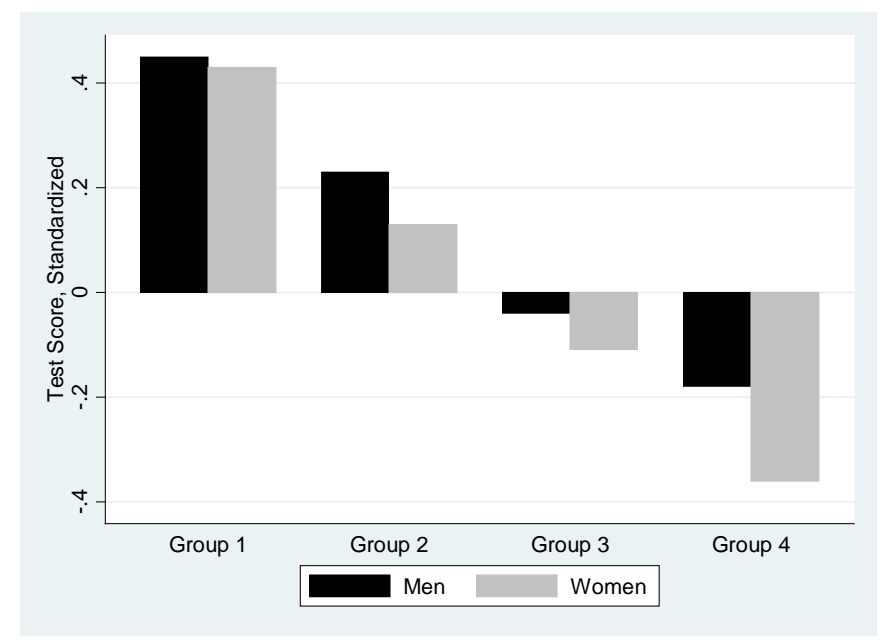

Figure 2: Cognitive Ability Measures for Add Health Men and Women at Wave I by SES Group (Group 1=high, Group 4=low)

Noncognitive skills: Economists' concept of productivity-enhancing 'skills' has become increasingly multidimensional. A growing body of research shows that individual traits other than cognitive ability, verbal and math skills are associated with key economic outcomes. The traits studied include perseverance, selfesteem, social competence and self-control, and they have been given, collectively, a variety of labels, including noncognitive skills, socio-emotional traits, socio-behavioral skills, and soft skills. In many cases, these characteristics have been found to be important contributors to achievement gaps. Heckman and Rubinstein (2001), for example, argue that the low returns to graduate equivalency diplomas (GEDs) in the United States is due to a deficit in noncognitive skills among GED-holders, as reflected in the higher prevalence of behaviors such as drug use, fighting, and shoplifting among this group. Other studies have shown that one apparent source of the gender gap in school success is the discrepancy between boys and girls in social skills and impulse control at school entry (DiPrete and Jennings, 2012; Bertrand and Pan, 2013).

Heckman and his collaborators have emphasized the importance of noncognitive skills for the construction of economic inequality and have argued that early interventions that enhance such skills for disadvantaged children (such as the Perry Preschool) could have substantial social payoffs, relative to later remedial education and training. We currently know very little, however, about how to measure these socio-emotional and other noncognitive traits, nor about the extent to which they should be regarded as 'skills' that are productive in all contexts. In practical terms, the indicators of noncognitive skills that have been used in empirical studies have often been measures of convenience ranging from actual behaviors, such as the parent and teacher reports of externalizing and internalizing behavior by young children and the criminal actions of teenagers and adults, to self-reports that reflect an individual's sense of mastery, selfesteem, or experiences of depression and anxiety. Personality inventories, developed by psychologists and found to be strongly correlated with many important economic outcomes, have also been identified as measures of noncognitive skills. 


\section{Traits and Education}

Why might the educational returns to traits such as personality vary by socioeconomic status? A simple model of individual traits and educational choices suggests that, if family background affects school and parental inputs to human capital production, the impact of individual traits on educational attainment are likely to vary across circumstances. ${ }^{4}$ A student will remain in school as long as the expected net return to an additional period of education (which we assume to be decreasing) remains positive. Let the expected marginal returns to a schooling level $s$ be $R_{s}=\gamma_{s}\left(\theta ; \mu_{s}\right)$, where $s \in\{1, \ldots, S\}$. $\theta$ is a vector of student traits such as personality and IQ and $\mu_{s}$ is a vector of other inputs such as school quality, peer influences, and parental assistance.

The net marginal returns to education can include the current enjoyment (or pain) of school attendance as well as the expected future benefits of education, and student decisions about continuing in school may be more or less myopic. In fact, intelligence and personality traits may affect education through the individual's ability to foresee future gains and to defer rewards. The supply of other inputs will depend on parental resources, including both income and education and, since cognitive and noncognitive traits are heritable, $\theta$ is likely to be correlated with $\mu$.

Parental and school inputs to the net returns to education may be complementary with, or substitutes for, components of $\theta$, so that the marginal returns to personality traits are likely to vary by parental SES or location. Extroversion, for example, may reduce the costs of continued education if peers are all expecting to go to college themselves, but increase costs if peers are dropping out. The conscientious are better at saving money, but personal savings will have little impact on college attendance if parents are wealthy. In general, we can expect students with identical traits who are in different situations to make different schooling choices.

\section{Personality}

Personality inventories measure "the relatively enduring patterns of thoughts, feelings, and behaviors that reflect the tendency to respond in certain ways under certain circumstances” (Roberts, 2009). Psychologists have found strong associations between personality traits and a broad range of behaviors and economic and social outcomes, including health and mortality, income, and relationship quality and stability (Roberts et al., 2007). Now that personality inventories are available in several large, populationrepresentative longitudinal surveys, economists have begun to study the relationship between personality and wages, wealth, and occupational choice, and to include personality traits among the individual traits that are labeled noncognitive skills. ${ }^{5}$

\footnotetext{
${ }^{4}$ Few studies have examined variation in the returns to cognitive and noncognitive skills by family socioeconomic status. Exceptions include a longitudinal study of twins that finds the education of low-IQ individuals is most sensitive to family background and resources while, for high-IQ individuals, shared genetic influences (including personality) are most important (Johnson, Deary, and Iacono, 2009). Lindqvist and Vestman (2011) find that noncognitive skills are much more important determinants of economic performance at the low end of the income distribution.
}

See the literature survey in Lundberg (2012). 
A number of different personality inventories have been developed by psychologists but the Fivefactor model, and in particular variants known as Big 5 models, is broadly accepted as a meaningful and consistent construct for describing human differences by psychologists (Goldberg, 1981). The five factors, with their definitions from the American Psychological Association Dictionary (2007), are:

Openness to experience (Intellect) - The tendency to be open to new aesthetic, cultural, or intellectual experiences.

Conscientiousness - The tendency to be organized, responsible, and hardworking.

Extraversion - An orientation of one's interests and energies toward the outer world of people and things rather than the inner world of subjective experience; characterized by positive affect and sociability.

Agreeableness - The tendency to act in a cooperative, unselfish manner.

Neuroticism (vs. Emotional stability) - A chronic level of emotional instability and proneness to psychological distress.

Personality is strongly heritable, and twin studies suggest that 40-60 percent of variation in personality is genetic (Bouchard and Loehlin, 2001). Many longitudinal studies have found that personality is extremely stable over the adult lifespan (though somewhat unstable in adolescence and early 20s) (Roberts and DelVecchio, 2000). Two important new studies of personality stability and exogeneity have been based on personality re-tests in the German Socioeconomic Panel Study (SOEP) and the Household, Income, and Labour Dynamics in Australia Survey (HILDA). Cobb-Clark and Schurer (2012) find little evidence that adverse life-events in employment, family, health affect personality over a four-year window in the Australian data, while Specht, Egloff, and Schmukle (2011) find some significant correlations between individual events and personality traits (7 out of a possible 60$)$, but no clear pattern of influences. ${ }^{6}$

Although the exogeneity of personality with respect to an individual's economic experiences and status is still under study, evidence is accumulating that personality traits are not simply proxies for preference parameters. The empirical associations between personality and preferences are very weak (Almlund et al., 2011; Rustichini et al., 2011) and the two sets of variables have largely independent effects on a large set of outcomes, including health, life satisfaction, wage, unemployment, and education (Becker et al., 2012).

The Add Health survey fielded a 20-item short-form version of the 50-item International Personality Item Pool-Five-Factor Model (IPIP-FFM) known as the Mini-IPIP (Donnellan et al., 2006). In my sample, the relationship between personality and SES varies by trait (see Figure 3), with neuroticism strongly correlated with both mother's education and family structure and openness positively associated with mother's education (conscientiousness and extraversion are not shown because their average levels are unrelated to family background). Agreeableness is moderately positively associated with family advantage for men, and more strongly so for women. Since emotional stability is a consistent predictor of high

\footnotetext{
${ }^{6}$ Controversy persists on this topic in psychology: Roberts has argued that personality continues to develop in adulthood in response to social role expectations and has shown in a number of studies a covariance between changes in social roles and changes in personality traits.
} 
earnings, the SES gradients in personality should, on net, contribute to the intergenerational transmission of income. $^{7}$
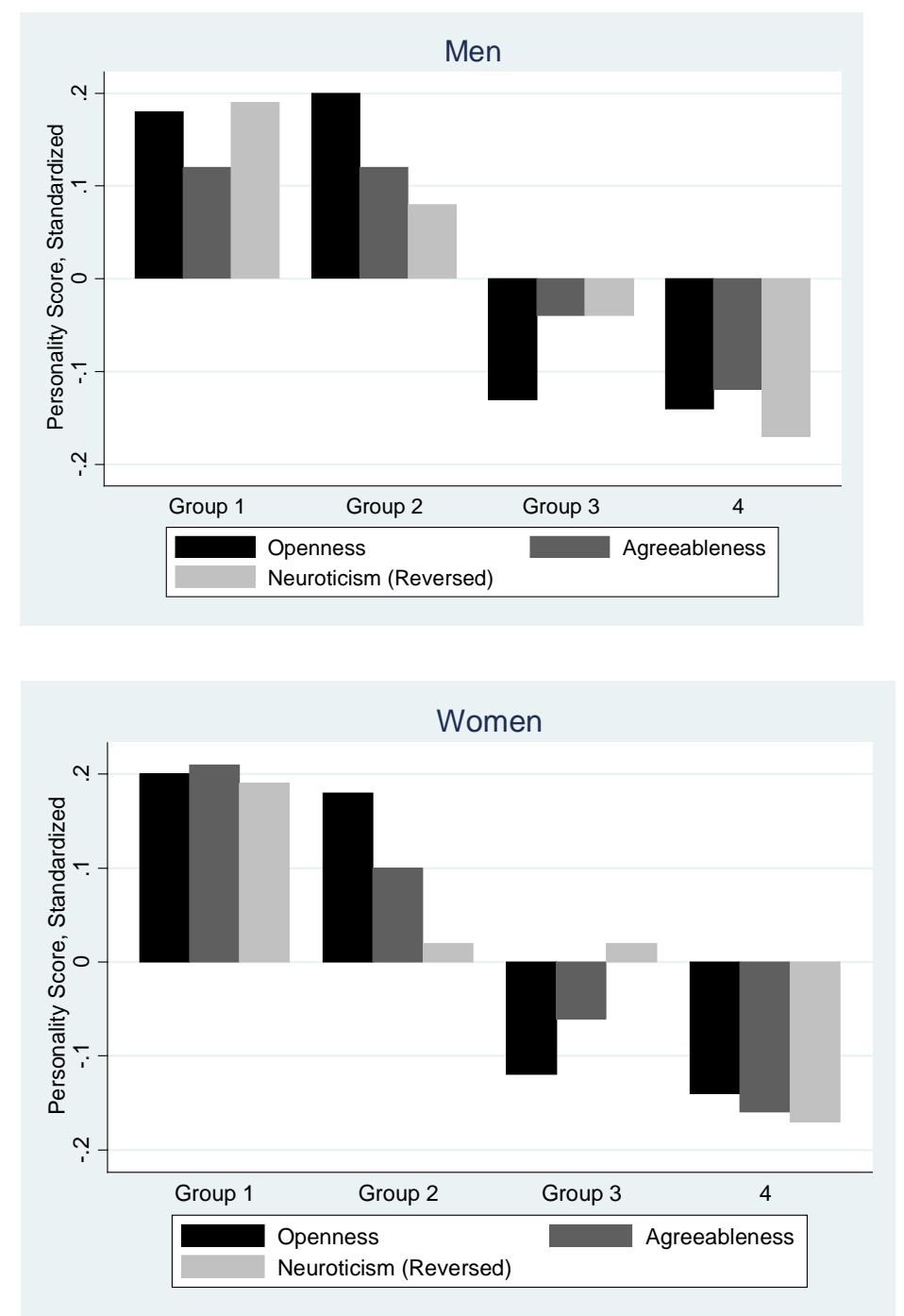

Figure 3: Personality Scores for Add Health Men and Women by SES Group (Group 1-high, Group 4=low)

\section{Personality and Education}

The study of personality originated as an attempt to understand why some highly-intelligent individuals perform well in school and in later life, while others do not. Pioneers in the development of IQ tests, such as Binet and Terman, were aware of the significance of qualities other than cognitive ability in determining success, and identified the key features of this dimension of 'character' as perseverance and

${ }^{7}$ See the review in Lundberg (2012a). Agreeableness tends to be associated with low earnings, especially for women, but this pattern is less consistent. 
attentiveness-aspects of the Big 5 trait, conscientiousness. ${ }^{8}$ Dependability, orderliness, and self-discipline are the hallmarks of the successful student to the early experts in personality psychology.

The relationship between personality and education has not received as much attention from economists as have personality effects on earnings and other labor market outcomes. ${ }^{9}$ A small number of empirical studies on personality and educational attainment find that openness and conscientiousness have positive effects on education, but these analyses do not in general control for cognitive ability, which is correlated with openness. Almlund et al. model educational attainment including measures of fluid and crystallized intelligence from the German SOEP study and find that, conditional on cognitive ability, conscientiousness is positively associated, and Neuroticism negatively associated, with education. More generally, a large literature in psychology and education finds that conscientiousness and behaviors related to conscientiousness, such as persistence and self-control, are strongly predictive of grades in school, and other measures of educational success. Duckworth et al. (2007) define a new trait, Grit, that is highly correlated with conscientiousness but focuses on persistence in the pursuit of long-term goals and show that it is an excellent predictor of academic achievement.

On the basis of the existing literature, we can expect conscientiousness and neuroticism, of the Big 5 personality traits, to predict individual educational attainment in the Add Health sample. A highly conscientious and emotionally stable student will be able to muster the focused effort and persistence required to study, get good grades, and navigate the college-admissions process. A question that receives little attention in this literature, however, is whether individuals from advantaged and disadvantaged backgrounds experience the same payoffs to these, or other, traits. Studies of educational success among disadvantaged children have focused on documenting deficiencies in skills that are believed to be conducive to educational success, rather than investigating the returns to these skills explicitly. The fact that the school, family, and community environments that will be supporting or distracting their scholarly efforts will be very different has received less consideration. ${ }^{10}$

\section{College Graduation, Personality, and Cognitive Ability}

What effects do personality traits have on the educational attainment of this young American sample, and do the returns to individual traits vary by family background? Using 4-year college graduation at Wave IV as a measure of attainment, I estimate a linear probability model that treats personality as a set of unobserved latent traits. Measurement error is likely to be a problem with self-reported, short-form personality inventories such as the 20-item IPIP in Add Health, and the latent variable model treats individual responses to each item on the personality scale as a noisy indicator of an unobserved personality trait. Each of the four items associated with personality trait $T_{j}$, then, is assumed to be:

$t_{i j}=\alpha_{i j}+T_{j} \beta_{i j}+\varepsilon_{i j} \quad$ for $\mathrm{i}=1, \ldots, 4$

\footnotetext{
${ }^{8}$ See the extended discussion of the history of personality psychology and its connections with the study of intelligence and the development of the IQ test in Almlund et al., p 10.

${ }^{9}$ Though Nandi and Nicoletti (2009) decompose the routes through which personality traits can influence earnings, including educational attainment and occupational choice, and they find that, while the positive effect of openness is completely explained by effects on education and occupation, the effects of extraversion, neuroticism, and agreeableness on earnings cannot.

${ }^{10}$ Studies of the effect of cognitive and noncognitive skills on earnings, however, find that noncognitive skills matter more for earnings at the lower end of the earnings distribution (Lindqvist and Vestman, 2011; Duckworth et al., 2012).
} 
with errors that are assumed to be independent. A linear probability model for college graduation as a function of the latent personality traits, risk aversion, and the AHPVT cognitive score was estimated for each gender-maternal education group, with the observed independent variables standardized and the latent variables assumed to have mean zero and standard deviation one. "The estimates for this model are reported in Table 1; full results for a wider array of models and subsamples are available in Lundberg (2012).

For men, there are distinct differences across socioeconomic groups in the determinants of college graduation. Conscientiousness and risk aversion are positively associated with college graduation only for men from relatively advantaged households, and have no effect on the educational attainment of men with less-educated mothers. Openness to experience, on the other hand, has a large positive effect on college graduation for less-advantaged men, and a very small and insignificant effect for the more-advantaged. Extraversion, similarly, is bad for the low-maternal-education group of men but not for the high-education group. The positive effects of agreeableness and emotional stability on the probability of college graduation are very similar for both groups. The marginal effect of cognitive ability, rather surprisingly, is significantly higher for men with high maternal education. Separate estimates for the four SES groups show that the significant effect of openness is common to the disadvantaged Groups 3 and 4, while the conscientiousness effect is limited to the most-advantaged subsample with highly-educated mothers and an intact household (as is the effect of risk aversion).

In general, SES differences in the effects of personality on college graduation for women are less distinct than they are for men-conscientiousness has a positive payoff for both groups, and extraversion has consistent negative effects. The impacts of openness to experience, however, are almost identical for women and for men: a large positive effect for the low-maternal-education groups and no effect for the high-education group. This is an interesting pattern, in the light of a growing body of evidence that boys are more vulnerable to socioeconomic disadvantage than are girls (Bertrand and Pan, 2012)

\footnotetext{
"This was estimated with the maximum likelihood version of the SEM (structural equation modeling) package in Stata 12. The results are very similar to those produced by a logit model in which personality trait measures are constructed by summing and standardizing the individual item responses.
} 
Table 1: Determinants of College Graduation by Mother's Education

(Linear Probability Model with Latent Personality Traits)

\begin{tabular}{lcccc}
\hline & \multicolumn{2}{c}{ Men } & \multicolumn{2}{c}{ Women } \\
& \multicolumn{2}{c}{ Mother's Education } & Mother's Education \\
& High & Low & High & Low \\
\hline \multirow{3}{*}{ Openness } & 0.014 & $0.053^{\cdots}$ & -0.003 & $0.045^{\cdots}$ \\
& $(0.014)$ & $(0.012)$ & $(0.013$ & $(0.012)$ \\
Conscientiousness & $0.039^{\cdots}$ & -0.003 & $0.037^{\cdots}$ & $0.028^{\cdots}$ \\
& $(0.012)$ & $(0.009)$ & $(0.010)$ & $(0.009)$ \\
Extraversion & -0.011 & $-0.030^{\cdots}$ & $-0.031 \cdots$ & $-0.050^{\cdots}$ \\
Agreeableness & $(0.012)$ & $(0.06)$ & $(0.012)$ & $(0.010)$ \\
& $0.053^{\cdots}$ & $0.045^{\cdots}$ & $0.071 \cdots$ & $0.036^{\cdots}$ \\
Neuroticism & $(0.014)$ & $(0.011)$ & $(0.014)$ & $(0.011)$ \\
& $-0.027^{\cdots}$ & $-0.029^{\cdots}$ & -0.057 & $-0.060^{\cdots}$ \\
Risk Aversion & $(0.012)$ & $(0.009)$ & $(0.011)$ & $(0.008)$ \\
& $0.030^{\cdots}$ & 0.002 & -0.014 & 0.002 \\
Cognitive ability & $(0.010)$ & $(0.007)$ & $(0.010)$ & $(0.007)$ \\
(AHPVT-Wave I) & $0.141^{\cdots}$ & $0.056 \cdots$ & $0.152^{\cdots}$ & $0.101^{\cdots}$ \\
& $(0.012)$ & $(0.007)$ & $(0.010)$ & $(0.007)$ \\
$N$ & & & & \\
& 2742 & 3514 & 3043 & 4166 \\
\hline
\end{tabular}

All models include age and race dummies.

Standard errors in parentheses

${ }^{\prime} p<.05,{ }^{\cdots} p<.01$

Estimating the model separately for black and white subsamples (not reported here) reveals that, conditional on mother's education, being black appears to be an additional dimension of disadvantage in terms of the marginal effects of personality traits. For each SES group, the positive effect of conscientiousness on educational attainment is weaker for black men and women, and the marginal effect of openness is stronger.

A number of caveats should guide the interpretation of these results. A primary issue is causality-if personality is malleable, some part of the correlation between traits measured at age 30 and college graduation may be due to the influence of education on personality rather than vice versa. Recent research on the stability and exogeneity of personality is reassuring on this point, but by no means definitive. This may be a difficult problem to overcome by, for example, finding data on personality traits measured at younger ages. The self-concept reflected in personality inventories, if it is influenced by education, is not likely to have been altered by the awarding of a degree but rather by years of school experiences, successes, and failures. Since the educational process that culminates in dropout or graduation begins early in life, no indicator of personality or other traits can be treated as pre-determined.

It is also important to recall that personality is heritable and we do not, in these data, have measures of parent's personality. The conscientious child is likely to have a conscientious parent, and if the parent's personality has any direct effect on school success or access to the path to higher education, the coefficients 
in Table 2 will reflect both influences. The same is true, of course, when we estimate the effects of cognitive ability on educational outcomes but are unable to control for parent's cognitive ability-which also may have direct effects on child school outcomes.

Finally, maternal education and family structure in middle school are crude measures of the environments that may affect the returns to student traits, as conceptualized by our model. The skills and propensities that are most adaptive in completing high school successfully, applying to colleges, and completing a four-year degree are likely to depend on many environmental factors, including the characteristics of schools and peers, financial constraints, and family influences throughout childhood and adolescence.

\section{Openness and Conscientiousness}

The results in the last section reveal some distinct differences across SES groups in the rates of return to personality traits, particularly for men. One of the most surprising is the absence of any significant positive effect of conscientiousness on college graduation for disadvantaged men, since this is the personality trait most closely associated with educational success by past research. One interpretation of this pattern is that persistence and playing by the rules, behaviors typical of the conscientious, are of more use in educational environments that are themselves orderly and consistent. This alone cannot explain the gender difference-conscientious girls from disadvantaged backgrounds are more likely to graduate from college, though conscientious boys are not-and raises the possibility of gendered effects of SES on schooling environments.

The other notable aspect of these results is the very strong and consistent role of openness to experience in sorting disadvantaged men and women among educational groups, though this trait plays no role in driving educational outcomes for those with more highly-educated mothers. ${ }^{12}$ Almlund et al. (2012) find no significant effect of openness on education after controlling for cognitive ability (which is correlated with openness), and the earlier literature on the effects of personality on health, income, and other outcomes find few consistent effects of this personality trait. Exceptions are studies of migration-Jokela (2009) finds that high openness predicts migration between and within states. In recent work on family outcomes, however, I have found that openness has strong positive effects on marriage delay and divorce (Lundberg, 2012). Also, Add Health respondents with high levels of openness live farther from their parents, and have less frequent contact with them (Borgo and Lundberg, 2012). Openness, which encompasses imagination, creativity, and an interest in novel experiences, is associated with mobility across several domains and with relatively weak interpersonal ties.

To understand some of the possible mechanisms that make openness a relatively valuable trait for disadvantaged young men and women, I examined the Add Health respondents' reports about college hopes and expectations in Wave I of the survey. The two key questions are:

"On a scale from 1 to 5 , where 1 is low and 5 is high, how much do you want to go to college?"

"On a scale from 1 to 5 , where 1 is low and 5 is high, how likely is it that you will go to college?"

\footnotetext{
${ }^{12}$ Preliminary estimates from the British Household Panel Survey show similar effects of openness on educational attainment for men, but not for women.
} 
Most children claim that they want to go to college and that they expect to do so. In fact, a majority of children in all SES groups answer 5 to the "want" question. Though most of the children in the disadvantaged groups will not, in fact, go to college, their responses to these questions are strongly predictive of both college attendance and college completion, especially for boys (Lundberg, 2012). Might openness affect educational attainment through these aspirations, which require that children have the imagination to see themselves take a path that their parents have not? In fact, adult openness to experience has strong positive effects on Wave I college hopes and expectations, but only for disadvantaged boys and girls (Lundberg, 2012).

In How Children Succeed, Paul Tough focuses on the importance of character in determining success, and the adverse effects of early disadvantage on many facets of character. He attributes the educational success of a poor Chicago teenager, who gets into college despite limited exposure to anyone who has been to college, to grit and conscientiousness, explaining:

It was as if Kewauna were taking part in an extended, high-stakes version of Walter Mischel's marshmallow experiment, except in this case, the choice on offer was that she could have one marshmallow now or she could work really hard for four years,...--and then get, not two marshmallows, but some kind of elegant French pastry she'd only vaguely heard of, like a napoleon. And Kewauna, miraculously, opted for the napoleon, even though she'd never tasted one before and didn't know anyone who had. She just had faith that it was going to be delicious.

Children who are able to wait for a second marshmallow are conscientious; children who can imagine a delicious reward that is completely outside their experience are more likely to be open to experience.

\section{Conclusions}

Recent research on the diverging fortunes of children from rich and poor families has focused on the skill disparities between these children-how they might arise and how they might be reduced. Another mechanism generating inequality that has received less attention are differences in the environments such children face that alter the returns to individual traits, leading similar children to have very different outcomes. Using data from a recent cohort of young Americans, I've shown here that such unequal opportunities may be important drivers of education inequality. Personality traits appear to have very different effects on college graduation rates of young men and women from different family backgrounds. Conscientiousness, which has been linked in past research to school success, was found to have no significant impact on the education of disadvantaged men, while openness to experience was an important correlate of college graduation only for less-advantaged men and women. Agreeableness and emotional stability have reasonably consistent positive effects on education for all groups.

Though personality traits have been included among the psychological characteristics social scientists have classed as noncognitive skills, there is very little support here for interpreting these scales as uni-dimensional skill measures such as IQ or verbal ability. Personality inventories describe an individual's characteristic modes of approaching situations and interacting with people. In the real world, the strategies that come naturally to a particular individual will work better in some circumstances than in others. 
The particular roles of openness to experience and conscientiousness in fostering the educational success of youth from different backgrounds, as well as related research on these traits, suggest an explanation based on the default path to adulthood faced by more and less-advantaged children. For an adolescent with well-educated parents and a relatively high income family, success in school can be achieved by remaining on a relatively well-marked and level path-studying and getting good grades. School authorities and parents will help these students acquire information and will assist with college applications and funding, and their peers will be planning for higher education. Barring very low ability or a rebellious nature, these students' desires to attend college should be attainable and the financial and other barriers to completion that impede low-income students will be absent. Supporting this notion of college as the status quo option is the positive effect of risk aversion on college graduation for only advantaged young men.

On the other hand, a young man or woman from a low-income household, with parents who have not attended college, will face much more limited material and informational resources for college attendance both at home and at school. Even so, one might expect persistence and hard work to have a substantial payoff in this environment as well, and so it appears for women, but not men. Instead, a personality trait associated with imagination and adventurousness-openness--seems to be the key feature that permits the crossing of SES barriers by this young cohort. Graduation from college for the disadvantaged requires both skills, in the form of cognitive ability and emotional stability, and the vision that openness signals.

This is exploratory empirical evidence, but it strongly suggests that, though endowments of skills are important for educational success, the environments in which these skills are deployed are important as well. Children from advantaged families will tend to be on the path to college. They need to avoid falling off that path and, for them, traits related to stability and persistence are keys to success. Disadvantaged youth, on the other hand, need to be immigrants to a world their parents and peers have little experience with, and openness to experience is a characteristic trait of successful migrants. ${ }^{13}$

What does this suggest about policy? As Heckman and his collaborators have argued, early investments in the skills of disadvantaged children, both cognitive and noncognitive, are likely to have a substantial payoff. What the Add Health results add to this is the suggestion that in designing these investments we need to be cognizant of the skill requirements specific to child's circumstances. Many interventions, proposed and actual, focus on skills related to conscientiousness, such as focus and persistence, and yet, for young men from disadvantaged backgrounds in this cohort, there was no apparent educational payoff to this trait. In addition to equalizing skill sets, we may want to pay attention to equalizing the environments that children (and their parents) will face as they progress through the school system. More research is required to identify the mechanisms that determine the returns to personality and other traits, and the extent to which the socioeconomic gap is due to family, peer, or school influences. In the dysfunctional schools, dangerous neighborhoods, and unstable households experienced by many poor children in American, there are many possible drivers for unequal opportunities.

\footnotetext{
${ }^{13}$ The alternative interpretations of these empirical patterns-that personality traits are proxies for other unobserved factors affecting educational success (such as parents' personality) or that educational trajectories mold personalities in different way in advantaged and disadvantaged environments-lead to restatement of this summary. On the one hand, disadvantaged youth and their parents must be immigrants and, on the other, disadvantaged youth must become immigrants, to achieve educational success.
} 


\section{References}

Almlund, Mathilde, Angela Lee Duckworth, James J. Heckman and Tim D. Kautz. 2011. "Personality Psychology and Economics." Handbook of the Economics of Education, Volume 4. E. A. Hanushek, S. J. Machin and L. Woessmann, eds. Amsterdam: North Holland, Elsevier Science, 1-182.

American Psychological Association. 2007. APA Dictionary of Psychology. Washington, DC, American Psychological Association.

Bailey, Martha J. and Susan M. Dynarski. 2011. "Inequality in Postsecondary Education.” Whither Opportunity? Rising Inequality, Schools, and Children's Life Chances. G.J. Duncan and R. J. Murnane, eds. New York: Russell Sage Foundation.

Becker, Anke, Thomas Deckers, Thomas J., Dohmen, Armin Falk, and Fabian Kosse. 2012. "The Relationship between Economic Preferences and Psychological Personality Measures.” IZA Discussion Papers 6470.

Bertrand, Marianne and Jessica Pan. 2013. "The Trouble with Boys: Social Influences and the Gender Gap in Disruptive Behavior.” American Economic Journal: Applied Economics, 5(1): 32-64.

Black, Sandra and Paul Devereux. 2011. "Recent Developments in Intergenerational Mobility." Handbook of Labor Economics, Volume 4b. O. Ashenfelter and D. Card, eds. Amsterdam: North Holland, Elsevier Science, 1487-1541.

Borgo, Seth and Shelly Lundberg. 2013. "Personality, Preferences, and Intergenerational Ties in Young Adulthood," presented at the Population Association of America Annual Meetings.

Bouchard, Thomas J. and John C. Loehlin. 2001. "Genes, Evolution, and Personality." Behavior Genetics, 31(3): 243-273.

Bound, John and Sarah Turner. 2011. "Dropouts and Diplomas: The Divergence in Collegiate Outcomes." Handbook of the Economics of Education, Volume 4. E. A. Hanushek, S. J. Machin and L. Woessmann, eds. Amsterdam: North Holland, Elsevier Science, 573-612.

Bowen, William G., Matthew M. Chingos, and Michael S. McPherson. 2009. Crossing the Finish Line: Completing College at America's Public Universities. Princeton, N.J.: Princeton University.

Cawley, John, James J. Heckman and Edward Vylactil. 2001. "Three Observations on Wages and Measured Cognitive Ability.” Labour Economics, 8(4): 419-442.

Cobb-Clark, Deborah A. and Stefanie Schurer. 2012. "The Stability of Big-Five Personality Traits." Economic Letters 115(1): 11-15.

Cunha, Flavio, James J. Heckman, and Susanne M. Schennach. 2010. "Estimating the Technology of Cognitive and Noncognitive Skill Formation.” Econometrica 78(3): 883-931.

DiPrete, Thomas A. and Jennifer L. Jennings. 2012. "Social and Behavioral Skills and the Gender Gap in Early Educational Achievement.” Social Science Research, 41(1): 1-15. 
Donnellan, M. Brent, Frederick L. Oswald, Brenden M. Baird and Richard E. Lucas. 2006. "The MiniIPIP Scales: Tiny-Yet-Effective Measures of the Big Five Factors of Personality." Psychological Assessment 18(2): 12.

Duckworth, Angela, Christopher Peterson, Michael D. Matthews and Dennis R. Kelly. 2007. "Grit: Perseverance and Passion for Long-Term Goals,” Journal of Personality and Social Psychology, 92(6), $1087-1101$.

Duckworth, Kathryn, GregJ. Duncan, Katja Kokko, Anna-Liisa Lyyra, Molly Metzger, and Sharon Simonton (2012). "The Relative Importance of Adolescent Skills and Behavior for Adult Earnings: A Cross-National Study,” Department of Quantitative Social Science Working Paper 12-03, University of London.

Duncan, Greg J. and Katherine Magnuson. 2011. "The Nature and Impact of Early Achievement Skills, Attention Skills, and Behavior Problems.” Whither Opportunity? Rising Inequality, Schools, and Children’s Life Chances. G.J. Duncan and R. J. Murnane, eds. New York: Russell Sage Foundation.

Goldberg, L.R. 1981. "Language and Individual Differences: The Search for Universals in Personality Lexicons," in Review of Personality and Social Psychology, Vol. 2, L. Wheeler, ed. 141-165. Sage, Beverly Hills, CA.

Gottfredson, Linda S. 2008. "Of What Value Is Intelligence?" in Wisc-Iv Applications for Clinical Assessment and Intervention. A. Prifitera, D. Saklofske and L. G. Weiss, eds. Amsterdan: Elsevier.

Harris, K.M., C.T. Halpern, E. Whitsel, J. Hussey, J. Tabor, P. Entzel, and J.R. Udry. 2009. "The National Longitudinal Study of Adolescent Health: Research Design.” [WWW document]. URL:

http://www.cpc.unc.edu/projects/addhealth/d

Heckman, James J. and Tim Kautz. 2012. "Hard Evidence on Soft Skills,” Labour Economics 19(4): 451464.

Heckman, James J. and Paul A. LaFontaine. 2010. "The American High School Graduation Rate: Trends and Levels," The Review of Economics and Statistics, 92(2): 244-262.

Heckman, James J. and Dimitriy V. Masterov. 2007. "The Productivity Argument for Investing in Young Children," Applied Economic Perspectives and Policy 29(3): 446-493.

Heckman, James J. and Yona Rubinstein. 2001. The Importance of Noncognitive Skills: Lessons from the GED Testing Program. American Economic Review 91 (2): 145-149.

Heckman, James J., Jora Stixrud and Sergio Urzua. 2006. The Effects of Cognitive and Noncognitive Abilities on Labor Market Outcomes and Social Behavior. Journal of Labor Economics 24(3): 411-482. 
Johnson, Wendy, Ian J. Deary, and William G. Iacono. 2009. "Genetic and Environmental Transactions Underlying Educational Attainment.” Intelligence 37: 466-478.

Jokela, Markus. 2009. “Personality Predicts Migration Within and Between U.S. States.” Journal of Research in Personality, 43(1): 79-83.

Lindqvist, Erik and Roine Vestman. 2011. "The Labor Market Returns to Cognitive and Noncognitive Ability: Evidence from the Swedish Enlistment.” American Economic Journal: Applied Economics 3(1): 101-128.

Lundberg, Shelly. 2012a. "Personality and Marital Surplus.” IZA Journal of Labor Economics 1:3.

Lundberg, Shelly. 2012b. "Personality and Educational Inequality."

Nandi, Alita and Cheti Nicoletti. 2009. "Explaining Personality Pay Gaps in the UK.” Institute for Social and Economic Research Working Paper.

Reardon, Sean F. 2011. "The Widening Academic Achievement Gap Between the Rich and the Poor: New Evidence and Possible Explanations.” Whither Opportunity? Rising Inequality, Schools, and Children's Life Chances. G.J. Duncan and R. J. Murnane, eds. New York: Russell Sage Foundation.

Roberts, Brent W. 2009. "Back to the future: Personality and Assessment and Personality Development.” Journal of Research in Personality, 43: 137-145.

Roberts, Brent W., Nathan R. Kuncel, Rebecca Shiner, Avshalom Caspi, and Lewis Goldberg. 2007. "The Power of Personality: The Comparative Validity of Personality Traits, Socioeconomic Status, and Cognitive Ability for Predicting Important Life Outcomes," Perpectives on Psychological Science 2(4): 313-345.

Roberts, Brent W. and Wendy F. DelVecchio. 2000. "The Rank-Order Consistency of Personality Traits from Childhood to Old Age: A Quantitative Review of Longitudinal Studies." Psychological Bulletin 126(1):3-25.

Rustichini, Aldo, DeYoung, Colin G., Anderson, Jon C. and Burks, Stephen V. 2012. "Toward the Integration of Personality Theory and Decision Theory in the Explanation of Economic and Health Behavior.” IZA Discussion Paper No. 6750.

Specht, Jule, Boris Egloff and Stefan C. Schmukle. 2011. "Stability and Change of Personality across the Life Course: The Impact of Age and Major Life Events on Mean-Level and Rank-Order Stability of the Big Five.” DIW Berlin, The German Socio-Economic Panel (SOEP).

Todd, Petra and Kenneth Wolpin. 2007. "The Production of Cognitive Achievement in Children: Home, School and Racial Test Score Gaps” Journal of Human Capital, 1(1): 91-136.

Tough, Paul. 2012. How Children Succeed: Grit, Curiosity, and the Hidden Power of Character. New York: Houghton Mifflin Harcourt. 